\title{
Dynamic Analysis of the Crank Mechanism through the Numerical Solution
}

\section{Marián Minárik, Ferdinand Bodnár}

Department of Mechanics, Mechanical Engineering and Design, Faculty of Environmental and Manufacturing Technology, Technical University in Zvolen, Študentská 26, 96001 Zvolen, e-mail: minarik@tuzvo.sk, e-mail: bodnar@tuzvo.sk

Dynamic analysis of crank mechanism is realised by relaxation method, where a connecting rod is modelled with three manners. In the first case the connecting rod is modelled as a rigid body, in the second case this one is modelled with two mass points and in the third case the connecting rod is modelled with three mass points. Results of all manners of modelling are compared and evaluated.

Keywords: Crank Mechanism, Dynamic Analysis, Kinematic Quantities

\section{Introduction}

Dynamic analysis of particular engine plant takes place on dynamic model of the system, which provides all needed force, weight and kinematics parameters for solution. Mathematical model consists of motion equations built-up for every body of the solved system. Solution of motion equations provides the wanted quantities which can be needed force actions for the given motion of the system, or kinematics quantities of individual bodies for the given force actions. Analysis of given mechanical system presents all desired variables from known introductive quantities. The dynamical analysis of the given mechanical system can be realised with different methods, e.g. by the relaxation method, used e.g. in [7] and [8], gearing down method of the weight and kinematics quantities or Lagrange's equation of motion of second kind, used e.g. in [4]. Choice of the concrete method is dependent on the magnitude of searched quantities of the given mechanical system [1], [2], [9].

The basic and simultaneously the most universal method of the dynamic analysis is relaxation method. The essence of the relaxation method is releasing of individual bodies of the created dynamic model of the system and the couplings between bodies are replaced by reaction forces as is used in the article [6]. Equations of motion and conditional equations are written for every released body. Conditional equations express the dependencies between kinematic and force quantities.

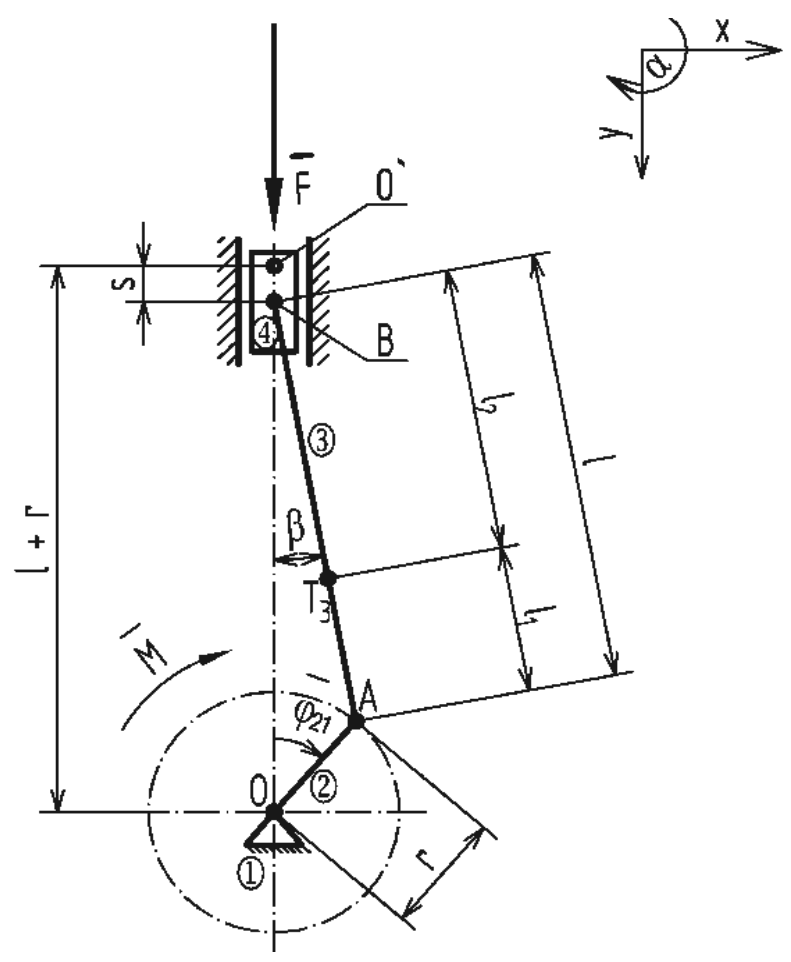

Fig. 1 The crank mechanism

Tab. 1 Input values

\begin{tabular}{|c|c|c|c|}
\hline crankshaft length & $r$ & 0.05 & $\mathrm{~m}$ \\
\hline connecting rod length & $l$ & 0.134 & $\mathrm{~m}$ \\
\hline crank angle & $\varphi$ & $0 \div 2 \pi$ & $\mathrm{rad}$ \\
\hline crankshaft rpm & $n_{21}$ & 2500 & ot.min $\min ^{-1}$ \\
\hline angular speed & $\omega_{21}$ & 261.7994 & $\mathrm{rad} . \mathrm{s}^{-1}$ \\
\hline force on piston & $F$ & 2300 & $\mathrm{~N}$ \\
\hline mass of the crank & $m_{2}$ & 0.9 & $\mathrm{~kg}$ \\
\hline mass of the connecting rod & $m_{3}$ & 0.94 & $\mathrm{~kg}$ \\
\hline mass of the piston & $m_{4}$ & 0.04 & $\mathrm{~kg}$ \\
\hline mass of the connecting rod in point $\mathrm{A}, 2$ & $m_{\mathrm{A} 2}$ & 0.638358 & $\mathrm{~kg}$ \\
\hline mass of the connecting rod in point $\mathrm{B}, 2$ & $m_{\mathrm{B} 2}$ & 0.301642 & $\mathrm{~kg}$ \\
\hline mass of the connecting rod in point $\mathrm{A}, 3$ & $m_{\mathrm{A} 3}$ & 0.305449 & $\mathrm{~kg}$ \\
\hline mass of the connecting rod in point $\mathrm{B}, 3$ & $m_{\mathrm{B} 3}$ & 0.144333 & $\mathrm{~kg}$ \\
\hline mass of the connecting rod in point T,3 & $m_{\mathrm{T} 3}$ & 0.490217 & $\mathrm{~kg}$ \\
\hline moment of inertia of the connecting rod & $I_{\mathrm{T} 3}$ & 0.00176 & kg. $\mathrm{m}^{2}$ \\
\hline complementary moment of inertia of the connecting rod & $I_{\mathrm{d}}$ & -0.00192 & kg.m $\mathrm{m}^{2}$ \\
\hline
\end{tabular}


The aim of our dynamic analysis is determining of magnitude of the moment transmitted on crankshaft (2) of the centric crank mechanism and the couplings reactions depending up the position of the crankshaft. Analyses are carried for three manners of modelling of the connecting rod. In the first case the connecting rod is modelled as a solid body, in the second case this one is substituted by two mass points and in the third case the connecting rod is modelled by three mass points. Results of all the said manners of modelling are compared.

The crankshaft rotates with uniform angular speed $\omega_{21}$ and on the piston acts the constant force $F$ from gas pressure. The mass's weights and friction forces are neglected. The input values of geometric and mass magnitudes are listed in the Tab. 1.

\section{Dynamic analysis}

Moment of mass inertia $I_{\mathrm{T}}$ and position $l_{2}$ of centroid of the used connecting rod are determined from the repeated measuring of the time of a physical pendulum oscillation [5]. For the given input values of the connecting rod: distance of holes axises of the connecting rod $l=134 \mathrm{~mm}$, mass of the connecting $\operatorname{rod} m=0.94 \mathrm{~kg}$, hole diameter for a pin $d=22 \mathrm{~mm}$, hole diameter for a crank $D=52 \mathrm{~mm}$, calculated values are: $l_{2}=91 \mathrm{~mm}$, $I_{\mathrm{T}}=0.00176 \mathrm{~kg} \cdot \mathrm{m}^{2}$.

\subsection{Dynamic analysis - the connecting rod is mo- delled as a solid body (version 1)}

A free-body diagram for released piston (4) from Fig. 1 is in the Fig. 2. The motion equation of the piston is

$$
m_{4} a_{41}=F-B_{34 y} .
$$

Because the piston acceleration in $x$ direction is zero, instead the motion equation it is the dependence

$$
N_{14}-B_{34 x}=0 \text {. }
$$

The connecting rod (3) in Fig. 1 executes a general motion. Motion equations of connecting rod are

$$
\begin{aligned}
& m_{3} a_{T 31 x}=B_{43 x}-A_{23 x}, \\
& m_{3} a_{T 31 y}=B_{43 y}-A_{23 y},
\end{aligned}
$$

where $\ddot{\varphi}_{31}$ and $I_{\mathrm{T} 3}$ are an angular acceleration and a moment of inertia of the connecting rod, respectively. Both are with respect to an axis that is perpendicular to the plane of motion of the connecting rod and passes through connecting rod centroid $T_{3}$.

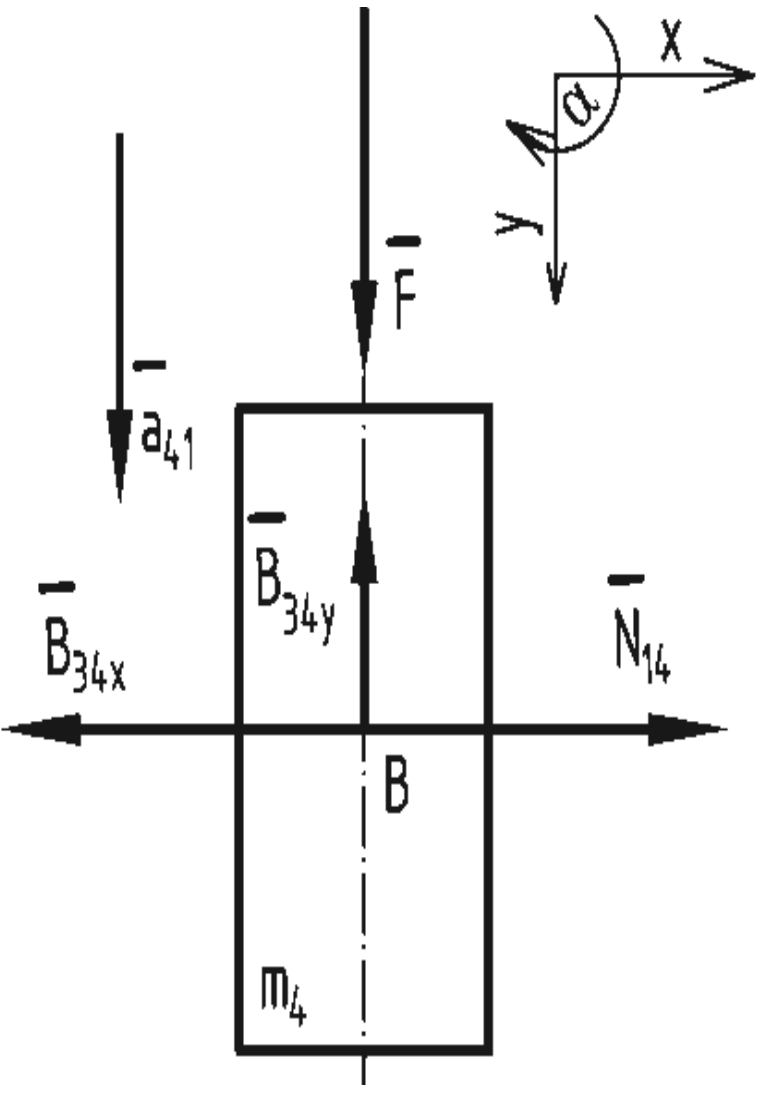

Fig. 2 Released piston

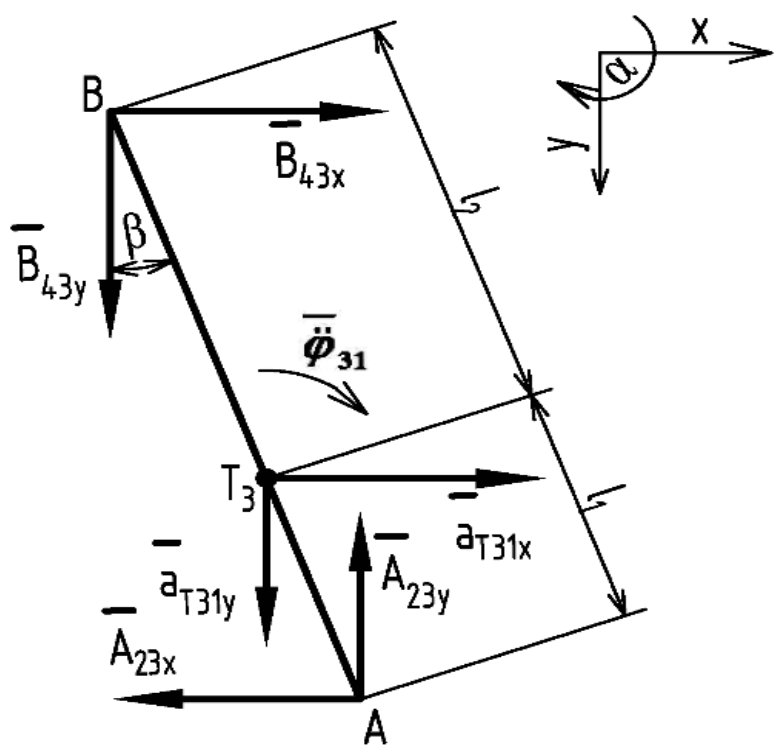

Fig. 3 Released connecting rod (version 1)

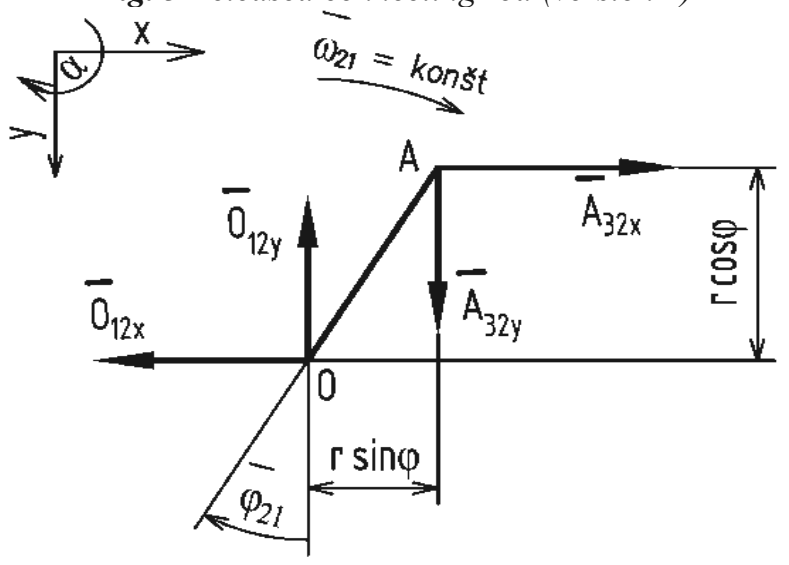

Fig. 4 Released crankshaft 
The crankshaft (2) of Fig. 1 rotates around the fixed axis, which passes through point $O$, with constant angular velocity $\omega_{21}$, (Fig. 4 ).

The moment transmitted on the crankshaft is

$$
M=r\left(A_{32 x} \cos \varphi_{21}+A_{32 y} \sin \varphi_{21}\right) .
$$

Because the crankshaft accelerations in both directions $x, y$ are zero, instead the motion equations there are the dependences

$$
\begin{aligned}
& A_{32 x}-O_{12 x}=0, \\
& A_{32 y}-O_{12 y}=0 .
\end{aligned}
$$

Solving of equations (1) through (8) requires to execute a kinematic analyse [3] for given constant angu-

lar velocity of the crankshaft $\omega_{21}$ and to formulate kinematic variables $a_{41}, a_{T 31 x}, a_{T 31 y}, \ddot{\varphi}_{31}$.

In agreement with Fig. 1 the piston position $s$ is

$$
s=l+r-r \cos \varphi_{21}-l \cos \beta
$$

At the close of kinematic analysis the piston acceleration $a_{41}$ in time $t$ is expressed

$$
a_{41}=\frac{\mathrm{d}^{2} s}{\mathrm{~d} t^{2}} \doteq \omega_{21}^{2} r\left(\cos \omega_{21} t+\lambda \cos 2 \omega_{21} t\right),
$$

where $\lambda=r / l$, accelerations of the gravity centre of the connecting rod $a_{\mathrm{T} 31 \mathrm{x}}, a_{\mathrm{T} 31 \mathrm{y}}$ are

$$
a_{T 31 x}=\ddot{x}_{T 3}=-l_{2} \lambda \omega_{21}^{2} \sin \omega_{21} t,
$$

$$
a_{T 31 y}=\ddot{y}_{T 3} \doteq \omega_{21}^{2}\left[r\left(\cos \omega_{21} t+\lambda \cos 2 \omega_{21} t\right)-l_{2} \lambda^{2} \cos 2 \omega_{21} t\right]
$$

and the angular acceleration of the connecting $\operatorname{rod} \alpha_{31}$ is

$$
\alpha_{31}=\ddot{\varphi}_{31}=-\omega_{21}^{2} \lambda \sin \omega_{21} t .
$$

For solving of equations (1) through (8) it is available the Newton's 3rd Law, that is

$$
\begin{aligned}
& B_{34}=B_{43}, \\
& A_{23}=A_{32} .
\end{aligned}
$$

Solution of equations (1) through (15) was done by numerical methods. Calculated results are visualised for one working cycle in Fig. 7 and Fig. 8.

\subsection{Dynamic analysis - connecting rod is modelled by mass points}

At solution of problems of the rigid body dynamics it is often convenient to replace a body by system of mass points. For such replacement at planar motion must be met these conditions:

- total weight of mass points must be equal to the weight of a body,

- position of gravity centre of the system of mass points must be the same with the gravity centre of the body,

- the moment of inertia of the body and of the system of mass points, to the axis passing through the gravity centre perpendicular to plane of movement, must be the same.

\section{Replacement of the connecting rod by two mass points (version 2)}

Position of the one mass point with mass $m_{A, 2}$ is determined by point $A$ and a position of the second point with the mass $m_{B, 2}$ is determined by point $B$. Conditional equations (16) for mass points have a form

$$
m_{3}=m_{A, 2}+m_{B, 2}, \quad m_{A, 2} l_{1}=m_{B, 2} l_{2}, \quad I_{T 3}=m_{A, 2} l_{1}^{2}+m_{B, 2} l_{2}^{2},
$$

at which, according to Fig. 5 , it is $l=l_{1}+l_{2}$.

Masses and positions of the mass points are unambiguously designated by $m_{A, 2}, l_{1}, m_{B, 2}, l_{2}$. It means, if one of these quantities is arbitrarily elected, the others follow from conditional equations. Because at replacement of the connecting rod by two mass points are elected positions of both points $l_{1}, l_{2}$, the others follow from (16)

$$
m_{A, 2}=m_{3} \frac{l_{2}}{l}, \quad m_{B, 2}=m_{3} \frac{l_{1}}{l} .
$$

And the moment of inertia must be compensated by the additional moment of inertia $I_{d}$

$$
I_{d}=I_{T 3}-\left(m_{A, 2} l_{1}^{2}+m_{B, 2} l_{2}^{2}\right)=I_{T 3}-m_{3} l_{1} l_{2},
$$

where $I_{\mathrm{T} 3}$ is the moment of inertia of the connecting rod with respect to an axis that is perpendicular to the plane of connecting rod motion and passes through centroid $T_{3}$ of the connecting rod.

Motion equations of the connecting rod on the basis of Fig. 5 are

$$
\begin{gathered}
m_{A, 2} a_{A} \sin \varphi_{21}+B_{43 x}-A_{23 x}=0 \\
-m_{B, 2} a_{B}-m_{A, 2} a_{A} \cos \varphi_{21}-A_{23 y}+B_{43 y}=0
\end{gathered}
$$

$$
\begin{aligned}
& I_{d} \ddot{\varphi}_{31}=-B_{43 y} l_{2} \sin \beta-m_{B, 2} a_{B} l_{2} \sin \beta-A_{23 y} l_{1} \sin \beta+ \\
& +m_{A, 2} a_{A} \cos \varphi_{21} l_{1} \sin \beta+A_{23 x} l_{1} \cos \beta+m_{A, 2} a_{A} \sin \varphi_{21} l_{1} \cos \beta+B_{43 x} l_{2} \cos \beta,
\end{aligned}
$$

Motion equations of remaining members of the mechanism are unchanged. at which $a_{A}=\omega_{21}^{2} r, a_{B}=a_{41}, \varphi_{21}=\omega_{21} t$, $D_{A, 2}=m_{A, 2} a_{A}, D_{B, 2}=m_{B, 2} a_{B}$. 


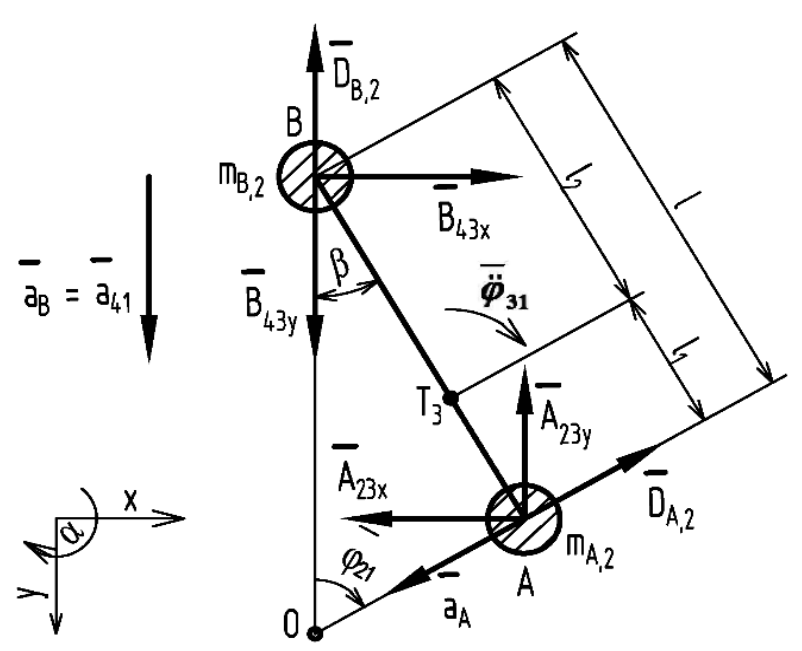

Fig. 5 Released connecting rod, replacement of the connecting rod by two mass points

Advantage of replacement of the connecting rod by two mass points is no need to know acceleration of the connecting rod centroid.

\section{Replacement of the connecting rod by three mass points (version 3)}

At solution of actual cases the connecting rod is most

$$
\begin{gathered}
m_{A, 3} a_{A} \sin \varphi_{21}-m_{T} a_{T 31 x}+B_{43 x}-A_{23 x}=0 \\
-m_{B, 3} a_{B}-m_{A, 3} a_{A} \cos \varphi_{21}-m_{T} a_{T 31 y}+B_{43 y}-A_{23 y}=0, \\
B_{43 x} l_{2} \cos \beta-B_{43 y} l_{2} \sin \beta-m_{B, 3} a_{B} l_{2} \sin \beta-A_{23 y} l_{1} \sin \beta+ \\
+m_{A, 3} a_{A} \cos \varphi_{21} l_{1} \sin \beta+A_{23 x} l_{1} \cos \beta+m_{A, 3} a_{A} \sin \varphi_{21} l_{1} \cos \beta=0,
\end{gathered}
$$

at which $a_{A}=\omega_{21}^{2} r, a_{B}=a_{41}, \varphi_{21}=\omega_{21} t, D_{A, 3}=m_{A, 3} a_{A}, D_{B, 3}=m_{B, 3} a_{B}$.

The conditional equations have a form

$$
\begin{gathered}
m_{A, 3}+m_{B, 3}+m_{T}=m_{3}, \\
I_{T 3}=m_{A, 3} l_{1}^{2}+m_{B, 3} l_{2}^{2}, \\
m_{A, 3} l_{1}=m_{B, 3} l_{2} .
\end{gathered}
$$

For given positions of mass points $A, B$, and $T_{3}$, see Fig. 6, masses $m_{A, 3}, m_{B, 3}, m_{T}$ are designated from (25), (26), (27)

$$
\begin{gathered}
m_{A, 3}=\frac{I_{T 3}}{l_{1} l}, \\
m_{B, 3}=\frac{I_{T 3}}{l_{2} l}, \\
m_{T}=m_{3}-\frac{I_{T 3}}{l_{1} l_{2}} .
\end{gathered}
$$

Solving of the crank mechanism at every replacement of the connecting rod by mass points requires the knowing of the centroid position as well as the inertia moment of the connecting rod to the axis passing through the gravity centre perpendicular to plane of motion.

Results of the solutions of the motion equations for individual versions are magnitudes of reactions $A_{x}, A_{y}, B_{x}$, $B_{y}$ and of the moment $M$ transmitted on the crankshaft. The reaction vector in point $A$ is

$$
\mathbf{A}=A_{x} \mathbf{i}+A_{y} \mathbf{j}
$$

and vector of reaction in point $B$ is

$$
\mathbf{B}=B_{x} \mathbf{i}+B_{y} \mathbf{j},
$$

where $\mathbf{i}$ and $\mathbf{j}$ are unit vectors in coordinate directions $x$, $y$, respectively.

Magnitudes of reaction vectors are

$$
\begin{aligned}
& A=\sqrt{A_{x}^{2}+A_{y}^{2}}, \\
& B=\sqrt{B_{x}^{2}+B_{y}^{2}} .
\end{aligned}
$$

\section{Results of Solution}

For every three presented dynamical models is carried out a numerical solving of motion equations. Results of numerical solving of monitored quantities are visualised for one working cycle in Fig. 7 through 15. 


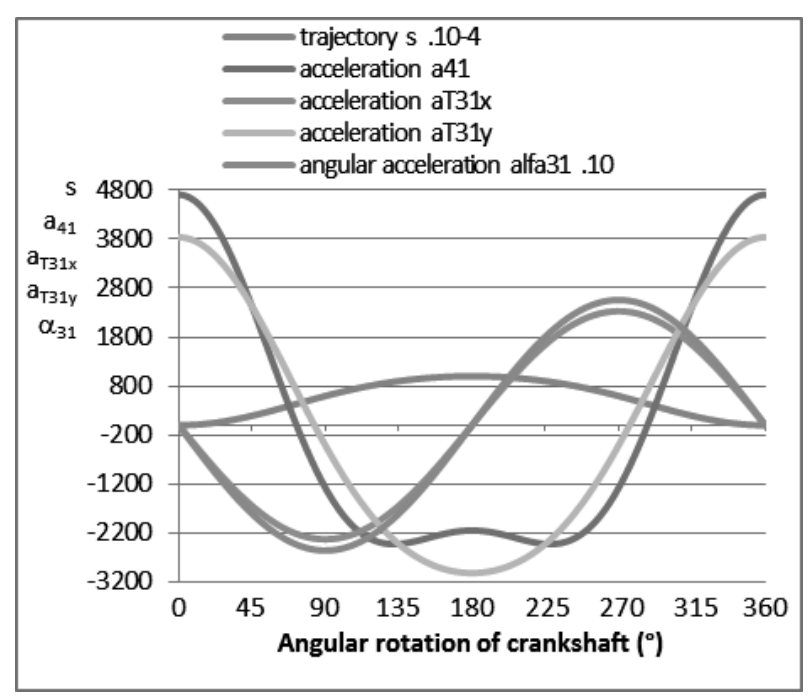

Fig. 7 The course of kinematic quantities

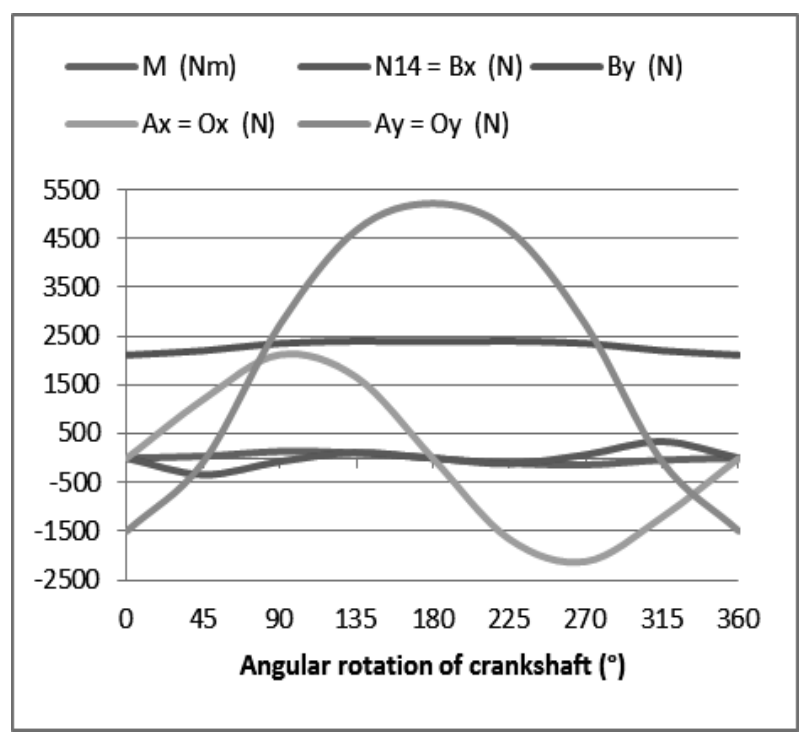

Fig. 8 The course of moment and reactions, version 1

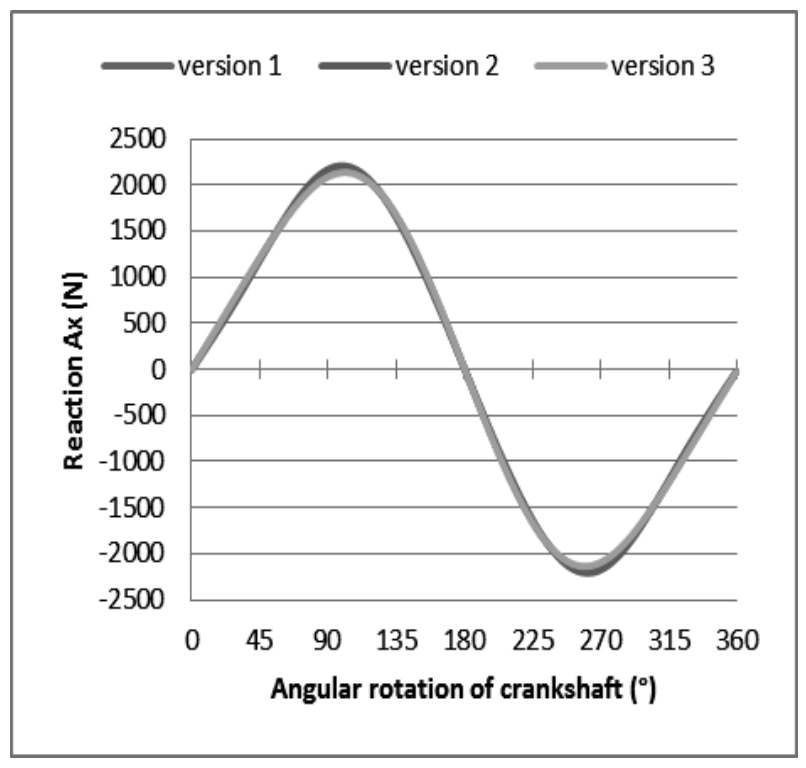

Fig. 9 The course of reaction $A_{23 x}$, version 1, 2, 3

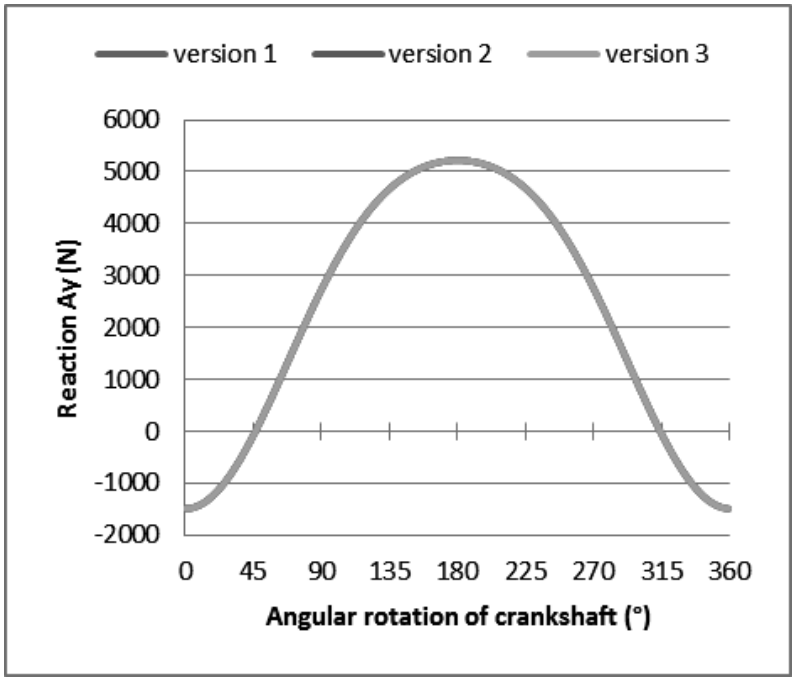

Fig. 10 The course of reaction $A_{23 y}$, version 1, 2, 3

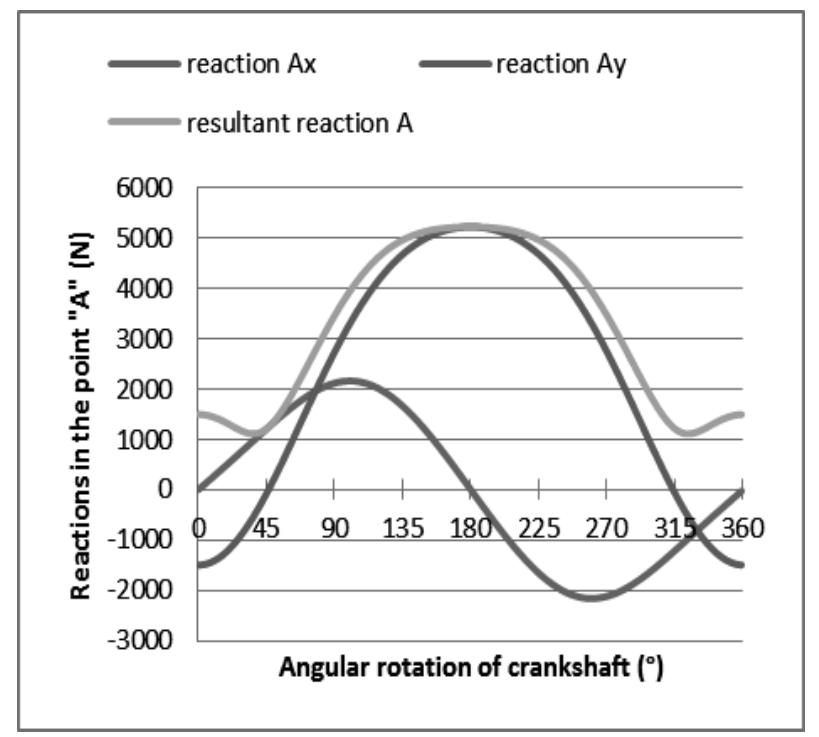

Fig. 11 Magnitudes of the components and of the resultant reaction in point $A$, version 1

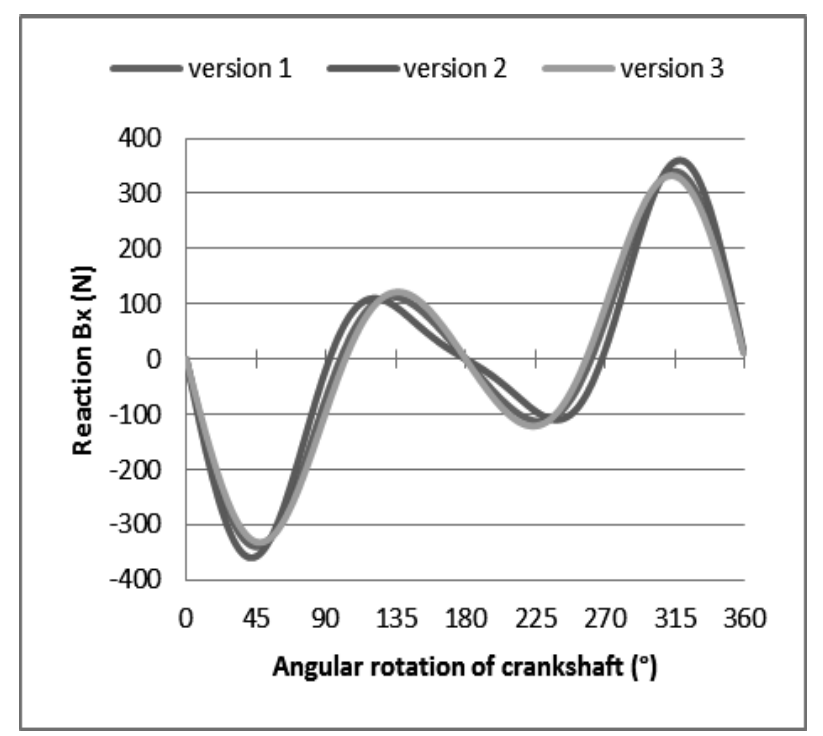

Fig. 12 The course of reaction $B_{43 x}$, version 1, 2, 3 


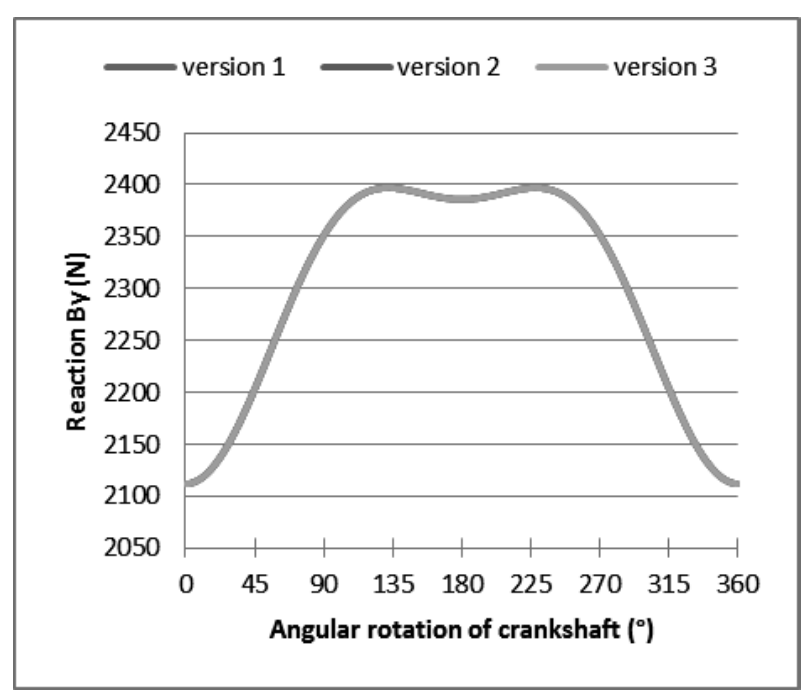

Fig. 13 The course of reaction $B_{43 y}$, version 1, 2, 3

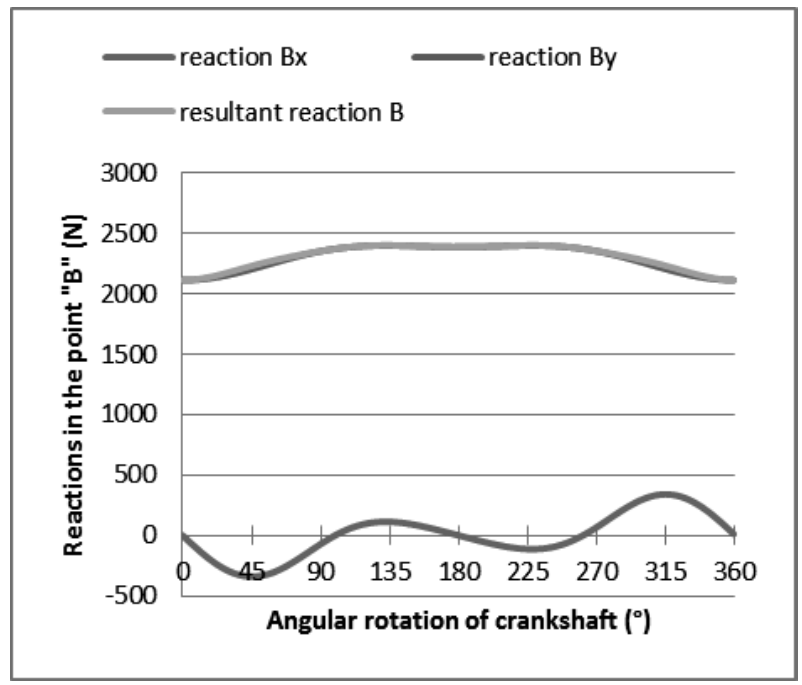

Fig. 14 Magnitudes of the components and of the resultant reaction in point $B$, version 1

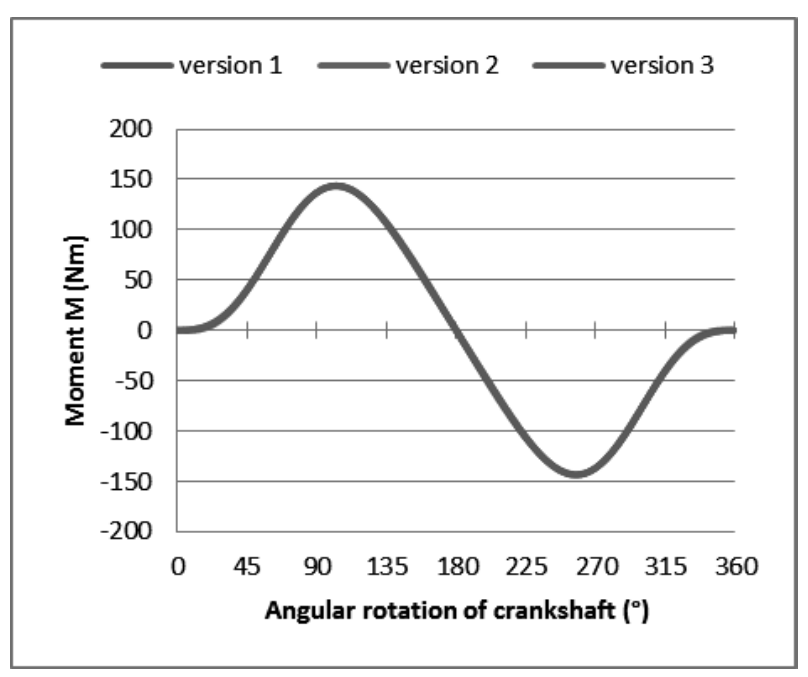

Fig. 15 The course of moment $M$, version 1, 2, 3

\section{Conclusions}

Figures 9 through 15 indicate a good agreement of calculated reactions $A_{x}, A_{y}, B_{x}, B_{y}, A, B$ as well as of the moment $M$ on the crankshaft in all realised cases of modelling. For practical application the connecting rod can be modelled as a solid body, or by two mass points and also by three mass points. At each elected model of the connecting rod it must be known location of its centroid and also a moment of inertia of a connecting rod to the axis passing through the gravity centre perpendicular to plane of movement. At modelling of connecting rod by the solid body it must be known also the acceleration of its centroid.

At comparing of the numeric values of monitored quantities however the differences in results are evident due to different analysis models. At comparing of the results among individual versions the results of the solid body model are considered to be accurate.

1. Values of the reactions $A_{y}$ and $B_{y}$ are the same at all used model within the whole cycle of work.

2. Extreme values of the reaction $A_{x}$ are smaller by over $0.35 \%$ at two mass points model and these ones are larger by over $0.17 \%$ at three mass points model.

3. Extreme values of the reaction $B_{x}$ are larger about a $5.26 \%$ at two mass points model and these ones are smaller about a $2.51 \%$ at three mass points model. These extreme values are at different crankshaft angles. Reaction $B_{x}$ proves the greatest displacement in dependence on the crankshaft angle.

4. The magnitude of the reaction $A$ is mostly influenced by its component $A_{y}$.

5. The magnitude of the reaction $B$ is mostly influenced by its component $B_{y}$.

6. The magnitude of the reaction $A$ is nearly equal at all versions in area of whole working cycle.

7. The magnitude of the reaction $B$ is nearly equal at all versions in area of whole working cycle.

8. Extreme values of the transferred moment on the crankshaft are smaller about a $0.34 \%$ at two mass points model and larger about a $0.16 \%$ at three mass points model.

9. Modelling of the connecting rod by three mass points provides the more accurate results as two mass points model.

\section{Acknowledgement}

This article was created as a part of the project „Progress and application of educational methods in the Mechanics of solids" No. 015TU Z-4/2019 by the Cultural and Educational Grant Agency the Ministry of Education, Science, Research and Sport of the Slovak Republic.

\section{References}

[1] BODNÁR, F. (2008). Mechanika. Vydavatel'stvo TU, Zvolen, ISBN 978-80-228-2016-5.

[2] GROS, D., HAUGER, W., SCHRÖDER, J., WALL, W. A., GOVINDJEE, S. (2014). Engineering Mechanics 3 - Dynamics. 2nd Edition, Springer, ISBN 978-3-642-53712-7.

[3] JANČINA, J., PEKÁREK, F. (1987). Kinematika. Alfa, Bratislava. 
[4] LIAO, Y., LIAO, B. (2019). Dynamics Modeling and Modal Analysis of Machine Tool Considering Joints Parameters, Manufacturing Technology, Vol. 19, No. 2, pp. 267-272. (2019), ISSN 12132489.

[5] MINÁRIK, M. (2018). Experimentálne zistenie momentu zotrvačnosti ojnice. In: Podpora kvality vyučovacieho procesu v oblasti Mechaniky telies prostredníctvom rozvoja edukačných metód, vedecký recenzovaný zborník, Zvolen, 2018, s. 2834. ISBN 978-80-228-3075-1.

[6] MINÁRIK, M., BODNÁR, F. (2018). Dynamická analýza centrického kl'ukového mechanizmu. In: Podpora kvality vyučovacieho procesu voblasti Mechaniky telies prostredníctvom rozvoja edukačných metód, vedecký recenzovaný zbornik, Zvolen, 2018, s. 35-51. ISBN 978-80-228-3075-1.

[7] SEGLA, S., KAMPO, J., SOUKUP, J. (2019). Dynamic Analysis and Optimization of the Planar Model of the Trolleybus Škoda 21Tr, Manufacturing Technology, Vol. 19, No. 3, pp. 487-491. (2019), ISSN 1213-2489.

[8] VAVRO, J., VAVRO, J. jr., PECUŠOVÁ, B., BURGET, M. (2018). Dynamic Analysis of Lever Mechanism for Manufacturing of Raw Tyres, $M a$ nufacturing Technology, Vol. 18, No. 1, pp. 145148. (2018), ISSN 1213-2489.

[9] ZÁHOREC, O., CABAN, S. (2002). Dynamika. Edícia vedeckej a odbornej literatúry, Strojnícka fakulta TU, Košice, ISBN 80-7099-825-3. 